\title{
LA CARIDAD CONTRA LA CIENCIA. UNA LUCHA IDEOLÓGICA ENTRE LA SOCIEDAD DE BENEFICENCIA DE LIMA CONTRA LA FACULTAD DE MEDICINA DE SAN FERNANDO, EN LA SEGUNDA MITAD DEL SIGLO XIX
}

\author{
ANTONIO COELLO RODRÍGUEZ \\ UNIVERSIDAD PRIVADA DEL NORTE \\ sequilao@yahoo.com
}

\section{RESUMEN}

El presente artículo explica, la lucha entablada entre la Sociedad de Beneficencia de Lima dirigida por una pequeña elite limeña contra la Facultad de Medicina de San Fernando, de Lima, representada por un cuerpo de galenos.

La Facultad de Medicina de San Fernando, tratará de organizar y dirigir una política higienista a desarrollarse en Lima, a la vez intentaba tomar el control de los centros hospitalarios, para poder así, poner en práctica los avances científicos que se venían desarrollando en otros países del viejo mundo. Asimismo los médicos al creerse los nuevos "ilustrados" de la república, manifestaran su opinión sobre diversos temas de la vida diaria, así como sobre la política. Por otra parte, la Sociedad de Beneficencia de Lima, se creía la encargada de dirigir y velar por el cuidado de los hospitales, pues al decir de ellos, estos estaban capacitados para organizar y administrar la ayuda hospitalaria, para lo cual incluso traerán a las Hermanas de la Caridad, procedentes de Chile, para que se hagan cargo de las boticas de los hospitales limeños.

Ante esta dicotomía, médicos y beneficencia harán sentir sus opiniones encontradas, en medios escritos, (periódicos, revistas especializadas, así como memorias anuales).

Palabras Claves: Lima, Salubridad, Hospitales, Sociedad de Beneficencia de Lima, Facultad de Medicina de Lima

\section{AbSTRACT}

This article explains the struggle between the Charity Society of Lima led by small elite against the Faculty of Medicine of San Fernando, Lima, represented by a body of doctors.

The Faculty of Medicine of San Fernando, was trying to organize and lead a hygienist policy to develop in Lima, while trying to take control of the hospitals, thus to implement the scientific advan- 
ces that were being developed in countries of the old-world. Also doctors believing themselves as the new "enlightened" of the republic, express their points of views on various issues of daily life as well as on policy. On the other hand, the Charity Society of Lima, in charge of directing and ensure the care of hospitals, saying they were able to organize and manage hospital aid, for which they even brought The Sisters of Charity, from Chile to be in charge of the pharmacies of hospitals in Lima .

Facing this dichotomy, doctors and the Charity Society expressed their opinions, in printed media (newspapers, magazines and annual reports).

KeYwords: Lima, Hygiene, Hospitals, Charity Society of Lima, Faculty of Medicine of Lima

"dos de los mayores triunfos obtenidos por el progreso médico, cuales son la nueva organización que ha recibido la Escuela y el aumento creciente del prestigio social de nuestra profesión" José Casimiro Ulloa 1859:169

\section{LIMA DURANTE LA DÉCADA DE 1850}

A mediados de la década de 1850, el Perú, estaba saliendo de una crisis política muy fuerte, que venía incluso desde los mismos tiempos de declarada nuestra independencia, caracterizada por la lucha continua de los diversos caudillos militares, una aguda crisis económica, sumado esto a constantes conflictos con las repúblicas vecinas (guerra con la Gran Colombia, guerra contra Bolivia y la misma confederación Peruano Boliviana).

Lima no escapaba a esta aguda crisis política y económica, incluso podemos imaginarnos como estarían otros aspectos de la vida diaria limeña, así como la de sus institucionales gubernamentales, salubridad, higiene, vida cultural y demás aspectos.

Como ejemplo podemos leer esta descripción de los primeros años de la república para reproducir la imagen de aquella Lima caracterizada por el desasosiego que reinaba por entonces “... Lima era reina de las ciudades sudamericanas orgullo del hemisferio occidental, donde el virrey sobrepasa en boato a los monarcas europeos, donde los comerciantes eran celebres por su opulencia, donde las ciencias y artes y el comercio florecían. Ay -tempora mutantur- que cambio. La desoladora y larga guerra civil habían puesto su mano férrea en la ciudad antes dichosa, y cuando la visite, en 1827, que triste contraste representaba. El nuevo gobierno en bancarrota y necesitado, los comerciantes insolventes, desaparecida la confianza, los templos despojados, vendidos los adornos de los habitantes, gente que vivía en palacios reducida a pobreza absoluta" (Haigh 1967: 31).

En lo concerniente a las Municipalidades, por ejemplo esta reflejaba la aguda crisis estatal y desde 1839 estuvieron suprimidas, con algunos años de apertura, en donde el cargo dependía más de la autoridad gubernamental que de la misma municipalidad, recién hacia 1856 se restablecerían las municipalidades $^{1}$, estas siempre se caracterizarían por sus ínfimos presupuestos, una institución acéfala, pese a que dicho establecimiento tenía como función velar por el servicio higiénico de la capital, su mala organización y falta de recursos no permitieron cumplir con dicho servicio "estando reducido aun en la capital misma de la republica a lo más indispensable y rudimentario”2.

1. El Monitor Medico, №1 junio de 18853.

2. El Monitor Medico, № 2 junio de 1885 
Pero no solamente en la Municipalidad de Lima sucedían estos avatares, podemos imaginarnos lo que pasaba con otras instituciones, como por ejemplo con la Sociedad de Beneficencia de Lima, ministerios y con la misma Universidad San Marcos, las cuales sufrían agobiantes crisis institucionales.

\section{La Sociedad de Beneficencia de Lima y SUS ORÍGENES}

Desde los tiempos coloniales, la asistencia social, estaba dirigida por una fuerte influencia de la caridad cristiana, la cual regentaba todo lo concerniente al funcionamiento de hospitales así como la salubridad, higiene y su administración. Es así que en Lima colonial existían por entonces el Hospicio de Pobres, la Casa de Huérfanos y Huérfanas, Casas de Amparadas; a esto debemos sumar los diferentes hospitales limeños, como Santa Ana, San Andrés, San Bartolomé, San Lázaro, Incurables. Posteriormente y hacia fines del virreinato, al crearse el Cementerio General, este también seria administrado por esta institución caritativa.

La Sociedad de Beneficencia de Lima ${ }^{3}$, fue creada en tiempos virreinales y posteriormente al llegar la emancipación, el reciente estado peruano la siguió protegiendo y brindando todo tipo de apoyo "Amparabase esta labor con las rentas del Ramo de Loterías y con el arriendo de la Plaza de Toros en acho. Con ello asumía el Estado definitivamente, la función, no solo de patrocinar, como en lo antiguo el ejercicio de la caridad social, sino manejar también su asistencia como atributo de la más genuina esencia política" 1945:777. ${ }^{4}$

Posteriormente en tiempos del presidente, Mariscal Luis de Orbegoso se emite un decreto del 17 de junio de 1834, estableciéndose la Sociedad de Beneficencia de Lima. Esta desde sus inicios cumplió una labor titánica, pues siempre tuvo que hacer frente a falencias económicas, esto asociado a los primeros años republicanos caracterizados por las luchas internas entre los caudillos militares, los cuales impedían que se consolide el orden económico y político del país.

Sin embargo aun así, con sus carencias económicas, la Sociedad de Beneficencia de Lima, hizo frente a las calamidades que azolaron Lima, como el Colera Morbus de 1837, viruela en 1839 y 1845 , fiebre amarilla 1868. Asimismo la labor de la Beneficencia no solo estuvo abocada a tiempos de paz, también participo en los álgidos momentos de guerras externas, como la de 1866 con España y la de 1879 contra Chile.

Al ser fundada la Sociedad de Beneficencia de Lima, esta coge las rentas de las vetustas instituciones de caridad colonial, cuya administración les fuera encargada, en varios casos estas rentas provenían de tiempos virreinales ${ }^{5}$. Posteriormente el Estado estuvo obligado a tener una partida necesaria para poder cubrir el rubro de asistencia social. Mientras tanto la Sociedad de Beneficencia de Lima tuvo como principal fuente de recurso a la Caja de Ahorros y el Ramo de Loterías ${ }^{6}$; otras rentas provenían por lo general de fundaciones y legados de origen particular o privado (olaechea 1933:627.)

3. Sobre la Sociedad de Beneficencia de Lima, puede consultarse la valiosa obra de Miguel Rabi, 2006

4. El Perú en cifras 1945:777

5. Los hospitales eran dueños de diversos predios rústicos y urbanos y con sus ventas y alquileres se obtenían fuertes suma de dinero, asimismo existía el impuesto llamado tomin de Hospital, la sisa, que era un impuesto a la venta de carnes; igualmente algunos hospitales obtenían diezmos, primicias, donaciones particulares y otros ingresos los cuales variaban de cantidad, por eso variaba la economía de esta institución de ayuda social

6. Para entender el desarrollo histórico de la Sociedad de Beneficencia de Lima, es necesario recurrir a sus Memorias Anuales, estas se hallan en la Biblioteca Nacional de Lima y en la misma sede de la actual Sociedad de Beneficencia Metropolitana de Lima, en todas ellas, el factor común es las quejas continuas sobre los pocos fondos económicos y como hacer frente a tal escasez 
Un hecho semejante con la Sociedad de Beneficencia de Lima, es el de otras repúblicas sudamericanas, en las cuales, las juntas y sociedades de beneficencias estuvieron conformadas por una "elite ilustrada y religiosa" y con un alto precepto de colaboración y ayuda mutua hacia el prójimo. Como ejemplo podemos citar el caso chileno ${ }^{7}$, muy semejante al nuestro

Al leer las diversas memorias de la Beneficencia uno podría enterarse de quienes eran sus miembros, denominados en muchos casos "Benefactores", entre los principales podríamos mencionar rápidamente al Presbítero Matías Maestro, quien distribuyo su fortuna entre varias instituciones piadosas y construyo el Cementerio General de Lima, así como la antigua Escuela de Medicina de San Fernando (Eguiguren 1946:115), asimismo fue Director General de la Sociedad de Beneficencia de Lima. Doña María Luisa López Maturana de Jacot, Condesa de Pozos Dulces, otorgo por testamento en Madrid varias fincas al Hospital de la Caridad de Lima. En 1850 Juan Ruiz Dávila y Hazaña Palacio, fundo el Hospicio para Señoras pobres y viudas de comerciantes ${ }^{8}$. En 1850 Antonio Chacón, bajo cuya administración, se realizaron grandes cambios estructurales a los principales hospitales limeños. En 1855 Juan Nepomuceno Vargas, fundo la Casa de Guadalupe, para mujeres pobres. En 1866 Pedro González de Candamo lego una fuerte cantidad de dinero para fundar el Colegio y Hospicio de Santa Rosa. En 1871 Jerónimo de Agüero, dejo sus cuantiosos bienes a la misma institución. En 1872 Bartolomé Manrique, construyo

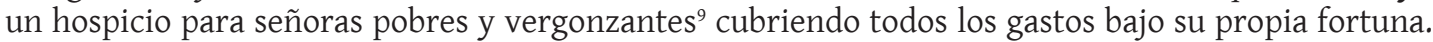
Francisco Carassa quien fuera varias veces presidente de la beneficencia, logrando grandes alcances en el desarrollo institucional. Por último, pero no menos importante podríamos mencionar al gran benefactor José Sevilla quien dueño de una gran fortuna, dejo gran cantidad de la misma, para que sea administrada por la misma Beneficencia, creando incluso una escuela básica de educación para niñas en Lima, conocida como Instituto Sevilla (Coello : 2007).

\section{De antigua Escuela a Facultad de Medicina}

La hoy Facultad de Medicina de San Fernando, fue inaugurada en tiempos del Virrey Fernando de Abascal hacia 1808, recibiendo el nombre de Colegio de Medicina y Cirugía de San Fernando esto gracias a la labor de su asesor Hipólito Unanue, este influyo enormemente en el pensamiento de dicho virrey quien se preocupó por instaurar un sistema de enseñanza medica en la capital del virreinato peruano. El primer local de dicha institución fue construido por el Presbítero Matías Maestro, inaugurándose en 1811 en la esquina de las calles de San Andrés y Sacramento de Santa Ana, frente a la plaza del mismo nombre (hoy Plaza Italia), cumpliéndose así la gran aspiración del sabio.

Sobre los orígenes y el desarrollo histórico de la Facultad de Medicina de San Fernando existe a la fecha una abundante bibliografía especializada ${ }^{10}$, de la misma forma hay un incremento por profesionales dedicados al tema de la historia de la medicina, así como de la salubridad, higiene y demás ramas anexas a ella.

7. Para el caso chileno puede consultarse, el trabajo de Ivovich y Torres 1937

8. Comúnmente conocido como Hospicio Ruiz Dávila, ubicado en la cuadra 5 del Jr. Ancash. Hoy este albergue que daba residencia a mujeres pobres, ha quedado convertido en un nuevo local del Congreso de la República, albergando a más funcionarios estatales, no habiendo cumplido con el bien testamentario de Ruiz Dávila y en un caso de atrevimiento mayor, el testamento de dicho benefactor que se guardaba en el Archivo Histórico de la hoy Beneficencia Pública de Lima ha desaparecido, como para borrar este acto de caridad y permitir este atropello contra nuestro patrimonio.

9. El Hospicio Manrique hoy se encuentra en el mismo lugar que fuera fundado, antigua Plaza de la Recoleta, hoy actual Plaza Francia.

10. Historia de la Medicina Peruana Juan B. Lastres. UNMSM, Lima 1951, Hospitales de Lima Colonial Siglos XVII -XIX. Ilder Mendieta Ocampo, Seminario de Historia Rural Andina. UNMSM, Lima 1990. Medicina y Salubridad en el Siglo XIX. Alejandro Salinas Sánchez, Seminario de Historia Rural Andina. UNMSM, Lima 2000. "El antiguo Hospital Real de San Andrés de Lima” Antonio Coello Rodríguez. En Arkinka. Año 7, número 84, Lima 2002 


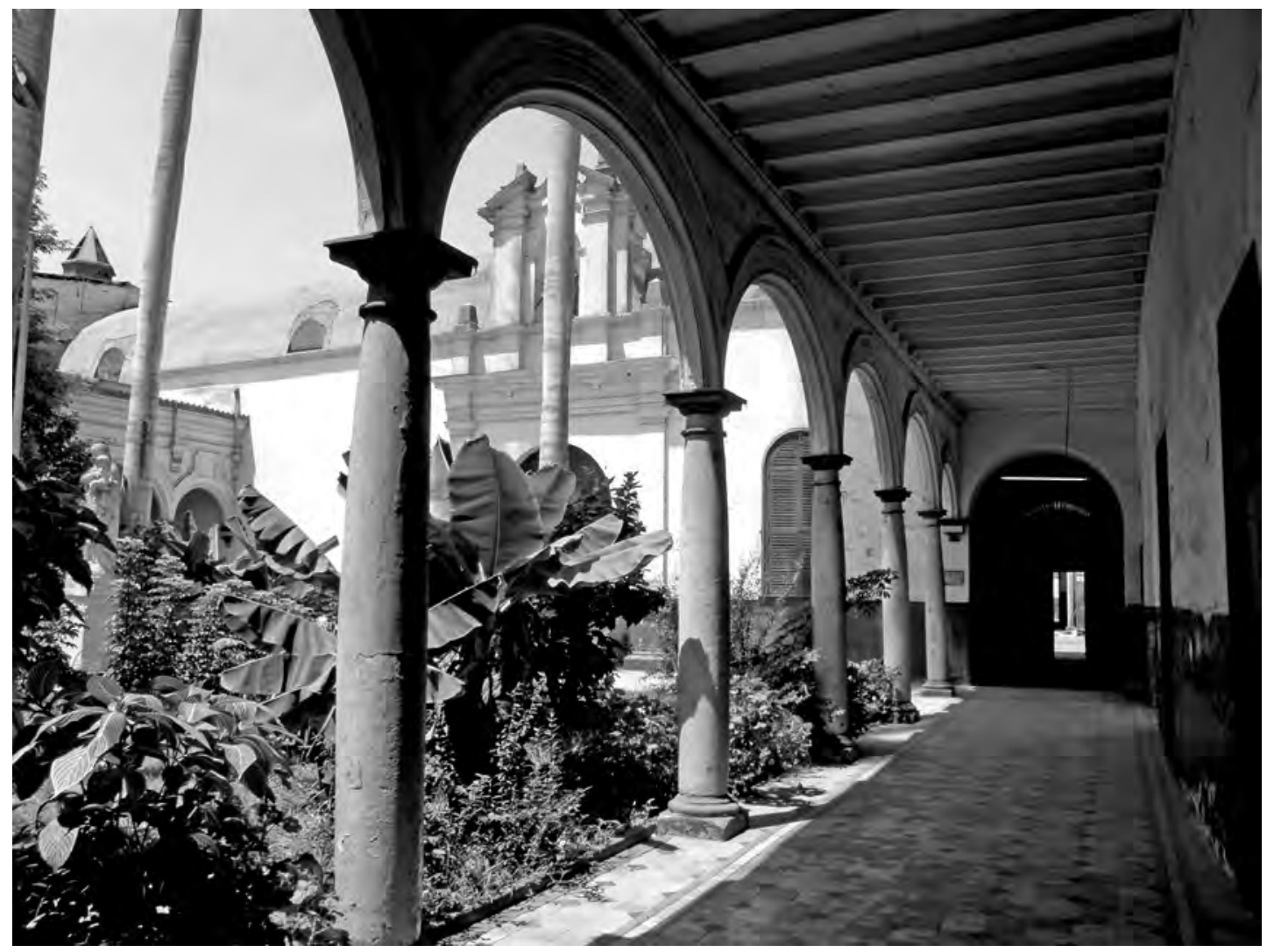

Hospital de San Andres Crédito Antonio Coello

Posteriormente y ya con aires emancipadores, hacia 1821, el antiguo Colegio de Medicina y Cirugía de San Fernando, cambiara de nombre, por el de Colegio de la Independencia (Uriel García 2004:52). Durante estos primeros años de desarrollo, el colegio atravesara serias crisis económicas e institucionales, las cuales son el fiel reflejo de la inestabilidad política peruana de sus primeros años republicanos. Esta crisis al decir de algunos autores se extendió hasta la décadas de 1840 e inicios del 1850. "Las penurias económicas trajeron muy pronto perturbación en su funcionamiento, que se reflejó en la disciplina, y es bastante para tener idea de las deficiencias que tuvo en el la enseñanza desde la iniciación de la Republica, a los diez u once años de su fundación, hasta 1842" (Olaechea 1933:624). Mientras que otra autoridad en la historia de la medicina, como Valdizan nos confirma lo anterior y nos dice al respecto. Entre los años 1821 y 1855, hubo años de clausura y años durante los cuales el Instituto hizo una vida tan precaria que parecía amenazar una eminente extinción ${ }^{11}$.

Hacia setiembre de 1856 se oficializara la conversión del Colegio de la Independencia en la recientemente creada Facultad de Medicina, gobierna el Perú el Presidente Constitucional, Ramón Castilla, será el, quien apruebe el Reglamento de funcionamiento, dicha Facultad de Medicina será la pionera en el estudio de medicina en el Perú, así como será un gran foco de prestigio científico en América del Sur. La Facultad de Medicina desde ese momento gozara de un enorme poder institucional, la cual dará su opinión en muchos caracteres, así mismo sus egresados, los galenos serán considerados 
los nuevos ilustrados de esta ciudad, una micro elite científica, ellos podrán opinar en cuanto tema quieran, ellos velaran por el ornato, salud e higiene de la ciudad. Incluso darán un salto cualitativo, pues muchos médicos formaran parte del partido civil, el cual apoyaría a Pardo, otros ingresarían al Congreso de la República ${ }^{12}$ donde mantendrán una fuerte actividad política, asimismo otros escribirán en diversos medios de prensa, sean en medios especializado (revistas científicas de medicina) así como en los diarios locales ${ }^{13}$.

Sin embargo este gran poder que van tomando poco a poco los médicos, no será bien visto, sobre todo por el pueblo, el cual no entenderá en muchos casos la lucha higiénica desarrollada por los médicos, y más aún su ciencia especializada, no gozara del agrado y comprensión. El "control médico" desde entonces será una especie de nueva inquisición aunque claro sin caer en el extremo de quemar brujas, pero si se encargaran de velar por el desarrollo de la especialización y profesionalismo médico. Tal como se da este fenómeno en Perú, sucederán estos cambios en otros lugares incluso muy distantes, Foucault (1977:22), reporta para Londres una serie de reacciones violentas de parte del pueblo, ocasionadas por pequeñas insurrecciones anti médicas, ocurridas en la segunda mitad del siglo XIX.

Pese a que el cuerpo médico no gozaba del aprecio popular, el estado peruano respaldo toda acción tomada por los galenos, aquí podríamos asumir que sucedió lo planteado por Foucault "La organización de un saber medico estatal, la normalización de la profesión médica, la subordinación de los médicos a una administración general y, por último, la integración de varios médicos en una organización medico estatal, llevan aparejados una serie de fenómenos enteramente nuevos que caracterizan lo que podría denominarse medicina de Estado" 1978:10.

Si trasponemos esta cita a la realidad peruana de aquel entonces, tendremos que la administración general en este caso, será aquí la recientemente convertida Escuela de Medicina, en Facultad de Medicina de San Fernando.

La agremiación médica, no solamente estuvo integrada por médicos, sino también por dentistas, farmacéuticos, parteras y flebotomianos, estos se hallaban unidos profesionalmente, además de estar unidos por otros lazos como participar en el bien común de la misma sociedad de ayuda mutua, lazos de mutualismo, bienestar económico, social y educativo (Forment 1999:22321.).

La Facultad de Medicina y la profesión médica, adquieren así un rol protagónico, que finalizo abruptamente con la Guerra del Pacifico (1879-1883) y la posterior ocupación de Lima, dejando trun-

12. José Mariano Macedo (1823-1894) representante al Congreso nacional por Puno. José Casimiro Ulloa (18291891) elegido varias veces parlamentario. Celso Bambaren (1834-1897), representante al congreso por Ancash. Miguel Colunga (1836-1914), diputado por Lima. Lino Alarco (1835-1903), Vicepresidente del Perú, en 1903 durante el Gobierno de Nicolás de Piérola.

13. José Casimiro Ulloa (1829-1891), mantendrá una agitada vida literaria, colaborador de diversos medios escritos, como Gaceta Médica de Lima, la Gaceta Judicial, Monitor Médico, El Rímac, El Nacional, El Comercio, La Revista de Lima. José Sebastián Barranca (1832-1909) prestigioso médico y botánico. Considerado un humanista total, realizo una traducción del drama Ollantay del quechua al castellano. Miguel E. Colunga (1836-1914) escribió interesantes trabajos sobre botánica y zoología. Pablo Patrón 1854-1910) gran colaborador de la Crónica Médica, en donde escribió temas netamente médicos, así como trabajos de historia peruana, entre los que podemos mencionar La sucesión de los Incas, Lima antigua, Origen del quechua y del aimara . Leonardo Villar (1825-1900) conspicuo colaborador de la Gaceta Medica de Lima. José Mariano Macedo (1823-1894) gran erudito, su conocimiento abarco las ciencias médicas, humanidades y sociales, realizo diversas expediciones arqueológicas y formo una gran colección de piezas prehispánicas, muchas de ellas hoy se hallan en museos alemanes. Mariano Arosemena Quesada (1818-1883), de origen panameño pero realizo sus estudios médicos en la Facultad de San Fernando, publicó numerosos trabajos sobre medicina legal, higiene y terapéutica médica. 
co un gran desarrollo científico, pero teniendo varios representantes médicos incluso reconocidos a nivel mundial.

\section{La Prensa Medica ilustrada y SU OPINIÓN CIENTífica}

Una mención especial para entender la prensa médica especializada y su voz científica, es referirnos a la famosa Revista Gaceta Médica de Lima. Órgano oficial de la Sociedad de Medicina y cuyo primer número apareció en 15 de agosto de $1856^{14}$. La Gaceta Medica de Lima fue una publicación eminentemente científica, de aparición quincenal, en donde los médicos opinaron tanto de temas específicamente médicos como tópicos de actualidad (situación política de la nación, así como temas relacionados a la higiene y salubridad de la Ciudad de Lima, desarrollo de la profesión médica, etc.), en sus páginas se mencionaran los avances científicos que ocurrían en el extranjero, así mismo se dará noticia de las enfermedades que azolaban la ciudad y diversos consejos para tratar a los enfermos, situación hospitalaria de la ciudad de Lima. A la fecha aún no se ha valorado el enorme valor e importancia que tuvo esta gran revista científica ${ }^{15}$

Los médicos a partir de su institucionalidad y profesionalismo poco a poco intervendrán en cuatro aspectos generales (Cf Foucault 1976:27) 1- Autoridad reglamentada con peso fiscal y estatal, la misma que podrá tomar decisiones a nivel de la ciudad, barrio. 2- Los médicos intervendrán no solamente en el campo de las enfermedades, sino también en lo relacionado a la construcción de nuevas viviendas, desagües, instalación de agua para el consumo humano, sistema de iluminación, sistema de calefacción, instalación de pisos, etc. Es decir el campo profesional se ampliara enormemente. 3- Ocupacion hospitalaria, poco a poco el cuerpo galeno en los temas relacionados al desarrollo de los hospitales, opinara respecto a los alimentos, visitas médicas, vestuario, pero lo que nunca podrá hacer será en lo concerniente a la administración propiamente dicha, pues está siempre será regentada por la Sociedad de Beneficencia de Lima, la cual ampliara la libertad de opinión y profesional de los médicos, pero nunca dejara que los bienes económicos sean administrados por ellos. 4- Introduccion de mecanismos de administración médica, lo cual no es otra cosa que el desarrollo de registros de ingreso y salida de los enfermos, así como comparación de los mismos, aparición de las visitas médicas y juntas médicas, donde debatirán las enfermedades y las acciones a tomar, esto llegara al cenit con la introducción de la ciencia estadística, la cual será considerada un arma letal y capaz de comprender el movimiento y conducir hacia el triunfo, ante las enfermedades ${ }^{16}$.

A lo largo del desarrollo histórico de los hospitales limeños, siempre existirán relaciones ásperas y duras entre la Sociedad de Beneficencia de Lima, poseedora de los hospitales de Lima, contra la Facultad de Medicina, la cual luchara constantemente por tomar el control de los mismos, en lo relacionado a su administración económica como en lo concerniente al desenvolvimiento y desarrollo de los hospitales mismos. Toda opinión elaborada por los médicos siempre será revisada por los ecónomos de la Sociedad de Beneficencia de Lima (Zarate 2005:95).

14. La Gaceta Medica de Lima, era la voz escrita y órgano oficial de la Sociedad de Medicina, fue su 1 Director Antonio Sánchez Almodóvar y sus redactores iniciales José Mariano Macedo, Francisco Rosas, José Casimiro Ulloa y Manuel N. Corpancho

15. La Gaceta Medica de Lima , tuvo corresponsales y suscripciones en diversas ciudades tales como Valparaíso (Chile) Guayaquil (Ecuador); mientras que por el lado peruano esta se dio a conocer en el Callao, Arequipa y Tacna

16. En variadas publicaciones de la Gaceta Medica, se presentan diversos cuadros estadísticos de las enfermedades ocurridas en Lima, así como en los hospitales, también se darán a conocer las estadísticas de nacimiento y mortandad de la ciudad de Lima. Ver la Revista Médica de Lima del 15 de agosto de 1856 "No son menos importantes los servicios que la estadística medica esta llamada a prestar a la ciencia y a la humanidad, ni menos provechosa los resultados que con ella debemos obtener en el curso de nuestras operaciones" 


\section{AÑ̃ DE 1856.}

\section{Gareta attédica of afima.}

ORGANO OFICIAL DE LA SQCIEDAD DE MEDICINA.

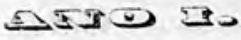

NUMER0 4. SETIEMBRE 30.

VERDAD EN LA CIENCIA,
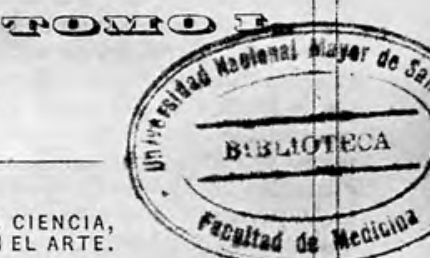

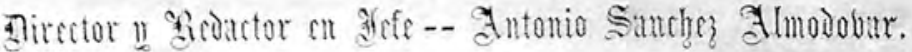

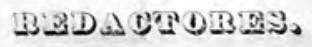

Tosé Muriano Mucedo. Francisco Rosas.
José Casimiro Ulloa.

Manuel N. Coipancho.

Mariano Arosemena Quezada.

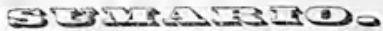

LA Gaceta.

Seccion Oftcial-Actas de la Sociedad de Medicina.

Crónica cientírica-Nota de la Junta Direc-

tiva de Mếdicina. na de Paris.

Folderix-Fantasia poetica Haschisch.

Crónica interion-Crónica de Hospitales.

INSERCIONes-Ozono.

Suplemfato-Trabajos academeos - Discurso del Dr. Bravo.

\section{CONDICIONES DE LA SUSCRICION.}

La Gaomta Medica sale cada 15 dias.-El precio de suscricion es de seis reales al mes.- Se admiten susericiones en la imprenta del Sr. Masias, calle de la Pescaderia, 127, Oficina de Redaccion-Calle de Piedra, 152.-Canıao, Sr. D. Santos Peña - Aregura, Sr. D. José María Rey de Castro-Tacna, Señor D. Carlos Basadre - VALPAraiso Sres. Santos Tornero y Ca.-Guiyaquin, Sres. Gallegos,-Cerro de Pasco, Sres. Lasurtegui. 
En diversas editoriales de la Gaceta Medica se dará a conocer continuas quejas y críticas hacia la Sociedad de Beneficencia de Lima, como a las acciones tomadas por esta. Pero no solamente se dará una opinión crítica hacia esta, también habrá palabras de aliento en acciones que la Facultad de Medicina de San Fernando, considere acertadas para la higienización de Lima.

Por ejemplo en la edición número 4 de la Gaceta Médica de Lima, se da la primera alerta sobre la situación hospitalaria de Lima y los cambios que deben aplicarse a esta, pues se pide que los médicos ingresen a atender a los enfermos.

De los estudiantes más adelantados que hoy cuenta el Colegio de Medicina, se nombrara un alumno interno y dos externos para cada departamento; los primeros con el cargo de desempeñar todas las obligaciones y los segundos encargados de la distribución de bebidas y curaciones. Para las ocurrencias apremiantes y graves que puedan ocurrir en la noche se dispone que un médico auxiliar duerma en el hospital. Ellos están obligados a prestar sus servicios profesionales a cualquier hora de la noche, cuando la gravedad y urgencia del caso así lo requieran ${ }^{17}$.

En otro artículo, escrito por el Dr. José Julián Bravo sobre el origen de la fiebre amarilla que azoló Lima en 1856, se menciona el estado de insalubridad de varias calles y barrios de Lima.

Así mismo en continuos números se abordara en la sección Higiene Publica, las recomendaciones a tener en lo relacionado al servicio de agua y las acequias ${ }^{18}$ el servicio de alumbrado por gas ${ }^{19}$, las habitaciones ${ }^{20}$ y demás temas de la vida cotidiana.

Volviendo al enfrentamiento entre la Sociedad de Beneficencia de Lima y la Facultad de Medicina de San Fernando. La Gaceta Medica mencionara los grandes cambios para mejoras ocurridos en los Hospitales de Lima y que fueron generados por los propios galenos, estos cambios estuvieron relacionados a la destrucción de las antiguas covachas e introducción de catres de fierro, apertura de grandes teatinas en los techos, lo cual permitió que circule un aire limpio y puro ${ }^{21}$, con estos cambios estructurales los hospitales dieron un salto cualitativo hacia una mejoría considerable.

Posteriormente, la Sociedad de Beneficencia de Lima, un poco hastiada de tanta critica, decidirá traer al Perú a las Hermanas de la Caridad para que se desempeñen en los Hospitales de Lima. Esta será una lucha propagandística en donde tanto médicos como la Sociedad de Beneficencia de Lima utilizaran todos los medios impresos disponibles para expresar su opinión y su validez. "La adopción por el Perú de la caritativa congregación de las Hermanas de San Vicente, ha venido a dar la última mano a este servicio y a poner a nuestros hospitales en tal estado que no avergonzarían a muchas ciudades del viejo continente. Las Hermanas de la Caridad han coronado los constantes esfuerzos de la Sociedad de Beneficencia, y han operado ciertamente en las casas que se han puesto bajo su dirección una verdadera metamorfosis, reemplazando el servicio estipendiado y mercenario que allí se hacía, por el servicio de evangélica caridad que su institución estaba llamada a desempeñar"22

Por otro lado en la Gaceta Medica se abrirá un fuerte debate sobre este caso, en un inicio esta acción gozara del respaldo médico, pero luego será blanco de agudas críticas. Han llegado las Hermanas de la Caridad tanto tiempo esperadas. La introducción de estas piadosas mujeres, producirá en nuestros

17. Cf. Gaceta Medica de Lima, 30 de setiembre de 1856. Artículo “Crónica de Hospitales", escrito por J. M. Macedo

18. Gaceta Medica de Lima, № 6 y 8, 1856; № 26 de 1857

19. Gaceta Medica de Lima, № 9, 1856

20. Gaceta Medica de Lima, № 10 de 1856 y 11 de 1857

21. Gaceta Medica de Lima, № 40 de 1858

22. La Revista de Lima, Tomo 1, junio de 1860:407 


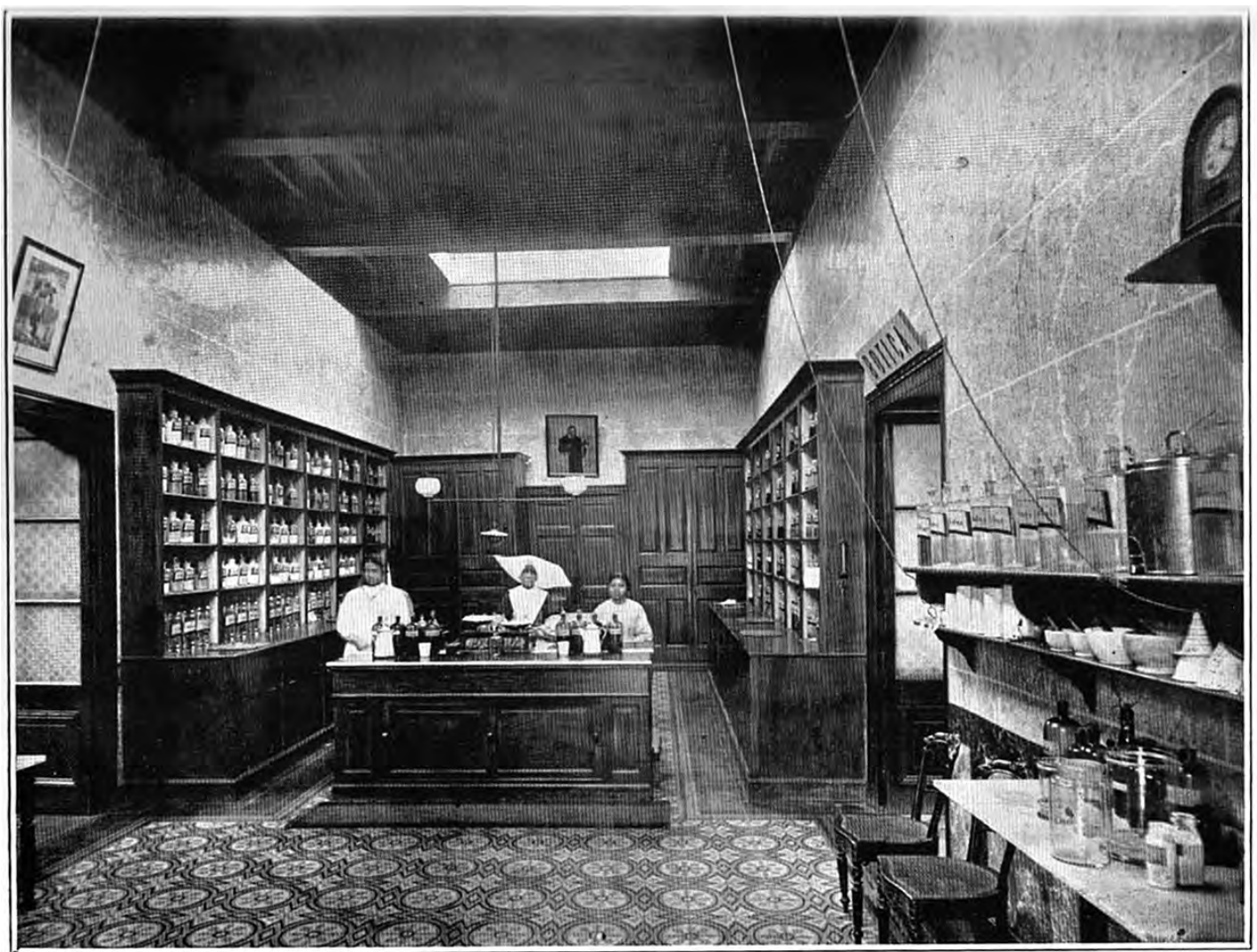

Botica del Hospital de Santa Ana. Crédito: Album de la Sociedad de Beneficencia de Lima

hospitales, una reforma saludable a la ciencia. Desde hoy podrán descansar los médicos tranquilos con la seguridad de que sus prescripciones serán ejecutadas con la severidad que demanda la ciencia. Felicitamos a la Sociedad de Beneficencia por esta medida de tan provechosa transcendencia ${ }^{23}$.

Pero luego, esta felicitación será convertida en una fuerte reprobación por parte de los propios médicos que antes lo halagaron. Tal como se puede ver en la editorial del 15 de octubre de 1858, en donde se critica la facultad dada por la Sociedad de Beneficencia para que las Hermanas de la Caridad administren la botica del Hospital de Santa Ana, sin la intervención de ningún farmacéutico ${ }^{24}$. Tal como era de esperarse los médicos se sienten respaldados pues según las leyes de aquel entonces, las boticas no pueden ser administradas por personas que no posean títulos. Los médicos critican esta acción copiada de Chile, en donde las boticas son administradas por las Hermanas de la Caridad y al decir de los galenos nacionales, "Chile es un pueblo atrasado que apenas comienza a hacer ensayos, especialmente en el orden científico, y que por lo mismo no puede concedérsele autoridad ninguna" (edición número 52, de 1858). Esta acción tomada por la Sociedad de Beneficencia de Lima luego se ampliara hacia el Hospital de San Andrés, ocasionando un mayor pesar a los médicos.

23. Cf. Gaceta Medica № 35, de 1858

24. Cf. Gaceta Medica № 50 y 51 , de 1858

25. Aquí nos referimos a los diversos locales hospitalarios (San Andrés, Santa Ana, etc.); así como a locales caritativos (Hospicio Ruiz Dávila, Hospicio Manrique etc.) 
"La Sociedad de Beneficencia es incapaz de corresponder al objeto para que ha sido creada; compuesta de personas estrañas (sic) a la Medicina, deben sin embargo ocuparse de las funciones más elevadas de la ciencia" Gaceta Medica de Lima, número 53, de 1858.

De manera reincidente, en la edición de febrero de 1859 de la Gaceta Medica de Lima, se seguirá criticando a las Hermanas de la Caridad acusándolas de falta de dulzura en el trato con los enfermos, de indiferencia y de abandono con ellos, así como a la falta absoluta de asistencia hacia los pacientes, sobre todo durante la noche. Asimismo recomienda como poder salir de la severa crisis económica que sufre la beneficencia.

Otras modificaciones sucedieron en las vetustas estructuras de los hospitales, San Andrés, Santa Ana, las cuales fueron realizadas por la misma beneficencia, pero contaron con la asesoría científica de los médicos.

Todas estas críticas a la Sociedad de Beneficencia de Lima, no serán escuchadas, pese a las continuas críticas y a los reiterados editoriales del cuerpo médico, convirtiendo esta situación en un constante monologo, efectuado solamente por los médicos.

\section{LA "voZ VALEDERA" DE LA SOCIEDAD \\ DE BENEFICENCIA DE LIMA}

Para defender la postura oficial, pero sobre todo conocedora de la verdad, se debe consultar las diversas memorias anuales que publicaba la Sociedad de Beneficencia de Lima, las cuales a la vez salían transcritas en los principales diarios capitalinos de Lima, durante los primeros días de enero de cada ano. En estas memorias, la beneficencia daba a conocer a la comunidad general sus avances y logros, esto como se comprenderá era una versión completamente diferente a la que aparecía en la Gaceta Medica.

Las memorias anuales, analizaban el estado económico de toda la corporación en sí, para después detallar una por una sus instituciones ${ }^{25}$.

En lo referente a la llegada al Perú de las Hermanas de la Caridad que ocasiono un fuerte debate entre ciencia, representada por los médicos y caridad, representada a su vez por el binomio beneficencia - órdenes religiosas, en la memoria anual de 1856, ya se anunciaba el que vendrían al Perú, las Hermanas de la Caridad, procedentes de Chile ${ }^{26}$. Posteriormente en la memoria consecutiva, es decir 1857-1858,

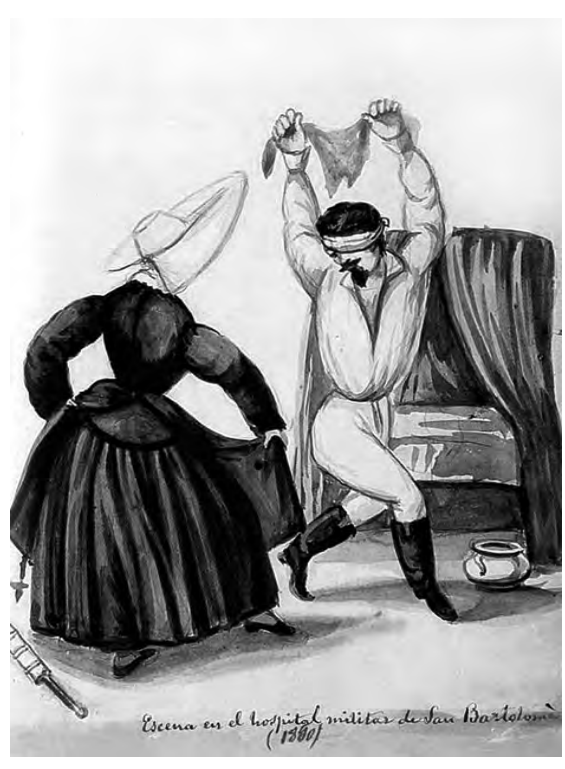

Lamina. Hermana de la Caridad, bailando Crédito: Pancho Fierro se anuncia ya que en el Hospital de San Andrés, se alojara a 30 hermanas de la Caridad "con las dependencias necesarias a su cómoda e independencia instalación, comunicando directamente e interiormente con las salas del Hospital y con la iglesia, dejando así satisfechas todas las exigencias de su servicio hospitalario y de sus deberes religiosos". Las Hermanas de la Caridad, se harían cargo de la botica, la cual según los "eruditos de la Beneficencia" era su especialidad, pues su conocimiento era

26. A dicho país, ya habían ingresado con mayor anticipación, a inicios de la década de 1850 . 
ya probado en otros países, así mismo la ropería estaría confiada al cuidado de ellas, y es una de las dependencias del hospital que da una idea favorable del orden y aseo que ellas dan ${ }^{27}$.

Otro ejemplo de esta pugna, la encontramos en la Memoria de 1864, en la cual la Sociedad de Beneficencia de Lima, protege de toda calumnia a las Hermanas de la Caridad, quienes no obstante de haber sido encargadas de manejar las boticas, siguen soportando un mal trato y prejuicios. ${ }^{28}$

Algo que parecería un encomio excesivo a la labor de las Hermanas de la Caridad, aparecerá en la Memoria de la Sociedad de Beneficencia de 1866, tratando así de presentar una imagen de mujeres caritativas y fuertes en un ambiente hostil y a veces no entendido por los hombres de ciencia "Debo, pues, hacer un acto de justicia a las Hermanas de la Caridad, principal resorte que comunica movimiento a cada una de esas máquinas, que les esta encomendad, y les da vigor y regularidad en sus funciones, y para decirlo de una vez, son el principio de orden, economía y moralidad, infiltrada en el régimen de cada hospital, y en los demás. Establecimientos puestos a su cuidado"

Esta lucha entre la ciencia que pugna por tomar el control de los centros hospitalarios continuara y será una constante, en los medios impresos, así como en la vida cotidiana. No teniendo cuando finalizar y habrá algunos que estén de acuerdo con los procedimientos de la Beneficencia y su caridad religiosa, pero otros apoyaran a la ciencia médica, quienes representaran el pensamiento de avanzada científica para el siglo XIX.

\section{BibLIOGRAFÍA}

Anónimo

1860 HIGIENE PÚBLICA. Apuntes dedicados a la Honorable Facultad de Medicina de esta capital. Tipografía del Comercio. Lima

CASTILLO VELASCO, Eduardo

1937 La Beneficencia Pública en Chile. Universidad Católica de Chile

BAUER, Brian and Coello, Antonio

2007 The Hospital of San Andres (Lima, Peru) and the Search for the Royal Mummies of the Incas. Field Museum of Natural History. Chicago

COELLO RODRIGUEZ, Antonio

2002 “El antiguo Hospital Real de San Andrés” En Arkinka Año 7, número 84. Lima

2007 "Labor educativa del Instituto Sevilla de Lima" En Historias. Revista de la Asociación Historia, Sociología y Ecología. Año 2, numero 2. Lima

FOUCAULT. Michel

1976 "La crisis de la medicina o la crisis de la anti medicina". En Educación Medica Salud Vol.10. Rio de Janeiro

1977 "Historia de la medicalización”. En Educación Medica Salud Vol.11. Rio de Janeiro

1978 “Incorporación del hospital en la tecnología moderna”. En Educación Medica Salud Vol.12. Rio de Janeiro

Gaceta Médica de Lima, Órgano Oficial de la Sociedad de Medicina. Lima. Varios años

27. Cf. Memoria Anual de la Beneficencia 1857-1858 


\section{GARCÍA CÁCERES, Uriel}

2004 "Los orígenes de la Medicina Moderna en el Peru", en Enciclopedia Temática del Perú, Tomo XII SALUD. Lima

HAIGH, Samuel

1971 “Relación de viajeros". En Colección Documental de la Independencia del Perú Tomo XXVI. Relaciones de viajeros. Lima

IVOVICH Estevan y TORRES Isauro

1932 Orígenes y Desarrollo de la Beneficencia Pública en Chile. Imprenta Universitaria. Santiago de Chile

LASTRES, Juan

1951 Historia de la Medicina, La Medicina en la Republica, Vol. III. UNMSM. Lima

LOSSIO, Jorge

2003 Acequias y Gallinazos. Salud ambiental en Lima del siglo XIX. IEP. Lima

MENDIETA OCAMPO, Ilder

1990 Hospitales de Lima Colonial. Siglos XVII-XIX. Seminario de Historia Rural Andino. UNMSM. Lima

Memoria de la Sociedad de Beneficencia de Lima, varios años. Lima

PINTO, Miguel y CANDIA Yolanda

2010 Curatos de Lima. Visitas eclesiásticas 1614-1915, SHRA UNMSM. Lima

RABÍ CHARA, Miguel

2006 Sociedad de Beneficencia de Lima Metropolitana. 172 años de Historia (1834-2006). Lima

RAMÓN, Gabriel

1999 La Muralla y los Callejones. Intervención urbana y proyecto político en Lima durante la segunda mitad del siglo XIX. SIDEA. Lima

SALINAS SÁNCHEZ, Alejandro

2000 Medicina y Salubridad en el Siglo XIX Seminario de Historia Rural Andino. UNMSM. Lima

Sociedad Peruana de Historia de la medicina

1945 Vida y obra de José Mariano Macedo. San Martí y Cía. S.A. Lima

VALDIZAN, Hermilio

1924 Publicaciones médicas del Doctor José Casimiro Ulloa. Lima

ZARATE. Eduardo

2003 "La Construcción del poder medico en el siglo XIX" En SITUA. Revista de la Facultad de Medicina de la Universidad Mayor de San Marcos, número 21, año 11. Lima

2005 Los Inicios de la Escuela de Medicina de Lima. ANR. Lima 